\title{
Personality disorder in older people: how common is it and what can be done?
}

\author{
Aparna Mordekar \& Sean A. Spence
}

Abstract There has been little systematic study of personality disorders in older people (65 years of age and above). However, with an ageing population worldwide we should expect to find increased numbers of people with Axis II disorders surviving into old age. We undertook a qualitative review of the recent literature concerning personality changes and disorders in older people, their prevalence and possible amelioration.

As the proportion of the population that survives to old age increases, we might expect to encounter more frequently in this group psychiatric conditions more commonly associated with early and middle adulthood. With this in mind, we have been interested in examining what is known about the prevalence and management of personality disorders among older people (65 years of age and above).

\section{Personality and age}

Although one's core personality is thought to remain stable over the adult years, modest variation may arise in terms of its expression with advancing age. For instance, an increase in obsessive-compulsive traits is common among older people and may reflect not so much a change in intrinsic personality as an adaptation of the person to failing powers or altered relationships and environments (Engels et al, 2003). The neurological substrate of reduced adaptability has also been variously investigated in the context of cerebrovascular pathology (Stone et al, 2004) and falling levels of central neurotransmitters (e.g. dopamine; Volkow et al, 1998).

Personality disorder (Box 1) is a controversial concept but the diagnosis remains pertinent in older people provided that a suitable account of long-standing dysfunction can be established that pre-dates presentation. In simple terms, personality disorder may be construed as a long-standing pattern of maladaptive interpersonal behaviour (Kroessler, 1990). So, although it might be considered very late for the condition to present in old age (perhaps marking the culmination of many unhappy events for the

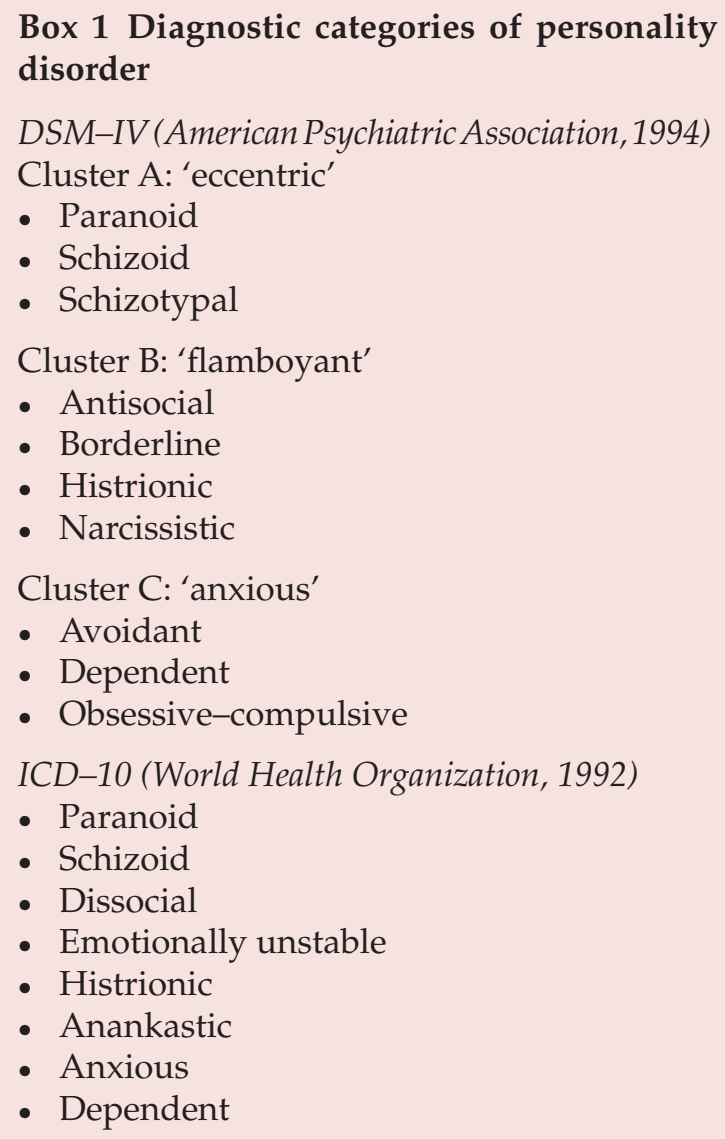

Box 1 Diagnostic categories of personality disorder

DSM-IV (American Psychiatric Association, 1994)

Cluster A: 'eccentric'

- Paranoid

- Schizoid

- Schizotypal

Cluster B: 'flamboyant'

- Antisocial

- Borderline

- Histrionic

- Narcissistic

Cluster C: 'anxious'

- Avoidant

- Dependent

- Obsessive-compulsive

ICD-10 (World Health Organization, 1992)

- Paranoid

- Schizoid

- Dissocial

- Emotionally unstable

- Histrionic

- Anankastic

- Anxious

- Dependent

individual) there might at least be the advantage of a considerable longitudinal history and pattern of behaviour for the examiner to investigate at the time of assessment.

Aparna Mordekar is a senior house officer on the Sheffield rotation, at Beighton Hospital (Seveneir's Road, Sheffield S20 1NZ, UK. Email: aparna.mordekar@sct.nhs.uk), and has an interest in liaison psychiatry. Sean Spence is Professor of General Adult Psychiatry at the University of Sheffield. His research is particularly concerned with the control of voluntary behaviour in health and disease. 


\section{Box 2 Barriers to diagnosis}

- Lack of co-informant

- Co-informant with little knowledge of patient's early life

- Unreliable patient and/or co-informant

- Cognitive impairment of patient and/or co-informant

- Co-informant's characteristics (e.g. shame, minimisation, embarrassment, guilt) affect their account

- Severe physical illness in patient

- Axis I and Axis II similarities, e.g. paranoid personality disorder $v$. paraphrenia; dissocial personality $v$. frontotemporal dementia

\section{Prevalence}

There are relatively few prevalence data concerning personality disorder in older people, yet ICD-10 asserts that such disorders are stable and enduring over time (World Health Organization, 1992: p. 200). Hence, by inference, personality disorder 'should' be seen among this stratum of the population. However, as age advances, certain 'problem' behaviours associated with personality disorder (e.g. impulsivity, aggression, promiscuity, fighting and law-breaking) might be expected to decline in frequency, while comorbid psychiatric disorders might enhance the expression of other dysfunctional traits: there is, for instance, a predominance of social withdrawal and major depressive and dysthymic disorders among older people (Devanand, 2002).

The prevalence of personality disorder among older people in the community has been estimated to be about 10\% (Box 1) (Abrams \& Horowitz, 1996).

Among older in-patients, personality disorder has been described in $6 \%$ of those with organic mental disorders and $24 \%$ of those with major depressive disorder (Kunik et al, 1994). In this sample, cluster $\mathrm{C}$ personality disorders (mainly the anxious and dependent types) were again more common. Patients with early-onset depression were more likely to exhibit personality dysfunction, mainly avoidant, dependent and 'not otherwise specified' (Kunik et al, 1994; Abrams \& Horowitz, 1996). There is also some evidence that among older patients with major depressive disorder, personality disorder is associated with a recurrent pattern of (depressive) illness (Kunik et al, 1994).

A further study, of 76 older people with dysthymia, found $31 \%$ (24) to have personality disorder. Of these, $17 \%$ (4) had obsessive-compulsive personality disorder, $12 \%$ (3) had avoidant personality disorder and 5\% (1) had borderline personality disorder (Devanand et al, 2000).

As alluded to above, there is thought to be a reduction with age in certain dissocial behaviours and a possible decline in cluster B personality disorders (Box 1). If true, such a decrease might be attributable to:

- a reduction in dramatic behaviour intrinsic to ageing

- age-related neurobiological changes that affect the manifestation of dissocial conduct

- increasing physical incapacity, reducing the ability to 'act out'

- attrition (through death) of those who have died by suicide or from other causes connected with personality disorder (e.g. recklessness)

- omission from studies of older people with antisocial personality disorder who are in prison or forensic psychiatric hospitals (Fazel et al, 2001)

- a cohort effect, whereby older age groups derive from cohorts who had lower (preexisting) levels of personality disorder than their younger comparators.

It is also possible that the natural history of the disorder is one of gradual improvement. Certainly, there is an anecdotal belief that certain personality disorders, for example borderline personality disorder, may 'burn out' with age. Indeed, the outcome of the latter is generally better than may be routinely acknowledged (Stone, 1993). Two-thirds are clinically well at follow-up, although they may retain mild residual symptoms (Stone et al, 1987). One study found that only one-quarter of people with an initial diagnosis of borderline personality disorder retained this full diagnosis at long-term follow-up (Zanarini, 2003). As the individual ages, it seems that impulsivity resolves first; next to improve is interpersonal functioning, and affective symptoms are the last to reduce or disappear.

Personality disorder among older prisoners in England and Wales has been studied by Fazel et al (2001). The prevalence was 30\% (in total), with avoidant and antisocial categories contributing most $(8.3 \%$ each), followed by anankastic $(7.9 \%)$, schizoid $(6.4 \%)$ and paranoid (3.4\%).

\section{Personality disorder as a risk factor for abuse}

If someone has a difficult personality, does this place them at increased risk as they become older and perhaps infirm? Of the potential risk factors for elder abuse identified by the House of Commons Health Committee (2004) identified, social isolation 


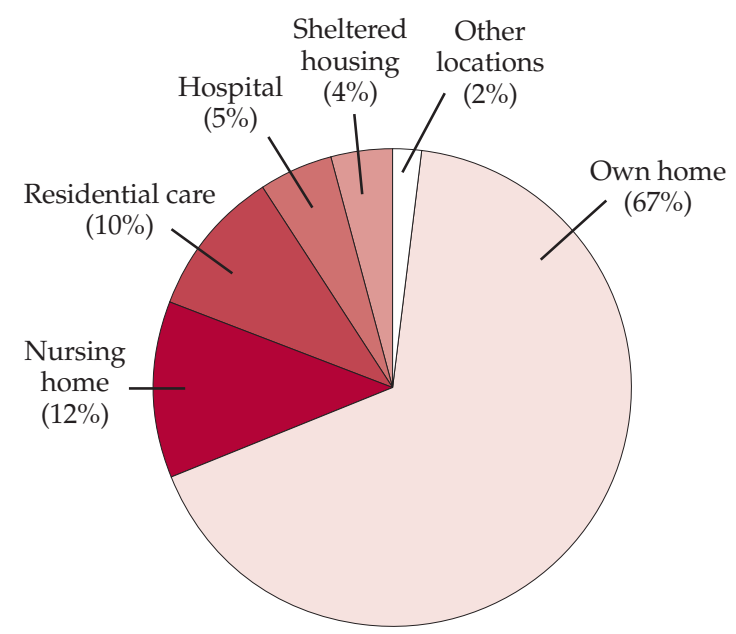

Fig. 1 Place of residence of people subjected to elder abuse in the UK (House of Commons Health Committee, 2004).

and a poor relationship with a carer might reflect personality difficulties; others, however, relate more to the perpetrator than the victim, for example dependence of the abuser on the person they abuse and a history of mental health problems, personality disorder, or drug and alcohol problems in the abuser. Although the public perception might be that older people are at greater risk of abuse in residential and nursing care, over two-thirds of elder abuse happens in the victims' own homes (Fig. 1).

Older people with anxious and dependent personality disorders may be particularly prone to abuse (Kurrle et al, 1991), as are people undergoing organic personality change (Hansberry et al, 2005). This may be due to their disinhibition, inability to communicate and/or lack of decisional capacity.

\section{Comorbidity associated with personality disorder}

Personality disorder is often associated with an Axis I psychiatric disorder, and this may compound problems for the potential patient and their carer(s). The link between depression and personality disorder seems well established (Devanand, 2002). Also, many patients with late-onset schizophrenia have never married, live alone and may have exhibited abnormal premorbid personality traits (Fuchs, 1999).

\section{Affective disorder}

Consistent data suggest that there is a strong relationship between personality disorder and
Box 3 Personality disorder and depression: a case example

A 69-year-old widow was referred for depressive symptoms following social stressors (a son had emigrated). She had shown little response to antidepressants prescribed by her general practitioner.

It transpired that she had withheld information regarding contact with psychiatric services in early adult life for recurrent self-harm (lacerations to her wrists).

Placing her recent stressors in the context of her longer-term problems helped her to adjust (she had experienced separations before and survived).

Her antidepressant medication was adjusted and she received follow-up with the mental health team. Her depression responded well and she returned to independent living.

depression. A case example is described in Box 3. The rate of personality disorder with a comorbid diagnosis of major depression was $24 \%$ in one study (Kunik et al, 1994). In older people with personality disorder, there is a high rate (73\%) of adult-onset rather than late-onset (geriatric) depression (45\%) (Camus et al, 1997).

In a sample of older patients with dysthymic disorder, a personality disorder co-occurred in a minority and mainly comprised the obsessivecompulsive and avoidant subtypes (Devanand et al, 2000).

\section{Anxiety disorder}

Anxiety is a frequent concomitant of depression. Individuals with cluster $C$ personality disorders seem more prone to developing anxiety disorder, phobias and acute stress disorder. Sanderson et al (1994) examined personality disorder in 347 patients with anxiety disorder and found that the most common were avoidant $(13 \%)$, obsessive-compulsive (11\%) and dependent (8\%) subtypes.

\section{Somatisation disorder}

Two-thirds of older people with depression have hypochondriacal ideas (De Alarcon, 1964); the main preoccupation being their bowels. In 30\% of these patients, hypochondriacal ideas (somatic concern or hypochondria) precede depressive symptomatology. 


\section{Substance misuse}

Certain personality disorders, especially those in clusters B and C, are more likely to involve problem alcohol use. In a study by Speer \& Bates (1992), it was found that older people are more likely to have the 'triple diagnosis' of personality disorder, alcohol dependence and depression.

\section{Diogenes syndrome}

Some people consider Diogenes syndrome to be an end stage of personality disorder. It refers to extreme self-neglect, unaccompanied by a medical or psychiatric condition sufficient to account for the condition. It can be seen as the response of someone with a particular personality type to old age and loneliness. It might also be a reaction to stress in older people with certain personality characteristics such as the schizotypal or anankastic (Rosenthal et al, 1999).

\section{Dementia}

Of course, personality changes occur in organic disorders even if they are not classified as personality disorder. Changes such as apathy and dysphoria have been described in Alzheimer's disease (Landes et al, 2005). Frontotemporal dementia is characterised by personality changes such as lack of insight, apathy and disinhibition. Not all individuals experience such change, but in those that do three patterns have been reported: change at the onset of dementia; ongoing change with disease progression; and change into disturbed behaviour (Petry et al, 1989). Carers often describe personality changes such as becoming 'out of touch', reliant on others, childish, irritable, unreasonable, unhappy, cold and cruel (Wattis, 1998). Some of these features may be attributable to organic changes, whereas others are a reaction to dementia. It is also possible that the dementing process 'releases' underlying behavioural propensities that the patient may have been better able to control when well.

\section{Management of personality disorder}

There is a very sparse literature on the management of personality disorder in older people: the basic principles are listed in Box 4. However, as mentioned earlier, personality disorder is commonly accompanied by an Axis I disorder, and judicious treatment of the latter may ameliorate certain aspects of the personality disturbance.

\section{Box 4 Principles of treating personality} disorder

- Form a therapeutic alliance

- Treat any comorbid Axis I disorder

- Adopt a consistent approach

- Use supportive cognitive psychotherapy

- Establish good links with other professionals

- Involve significant others where possible

\section{Role of medication in treatment}

Medications are often used to treat the functional illnesses comorbid with personality disorders.

The mainstays of pharmacological treatment of depressive disorders are obviously the antidepressants. However, because of the frailty and physiological changes that occur with age, they are often started at low doses and increased slowly. The most commonly used antidepressants are the selective serotonin reuptake inhibitors (SSRIs), owing to their safer side-effect profile and less frequent interactions with other medications. Kunik et al (1994) reported that older in-patients both with and without personality disorder who had major depression benefitted equally from treatment, primarily antidepressant medication or electroconvulsive therapy (ECT). Conversely, Thompson et al (1987) found that concomitant personality disorder in older patients with major depression decreased the likelihood of response to psychotherapy.

Low-dose antipsychotic drugs are mainly used to control agitation and psychotic symptoms (Bouman \& Pinner, 2002). Their appropriate use in older people has become an area of increasing debate: typical antipsychotics are generally more likely to induce extrapyramidal side-effects, but there are concerns over the safety of the atypicals in this age group (Herrmann \& Lanctot, 2006). The use of minimal effective doses seems vital here (as elsewhere in medicine).

\section{Role of psychotherapy in treatment}

Some expressions of troublesome personality traits will resolve with treatment of an associated or underlying functional disorder. However, when a patient has persistent or residual symptoms of personality disorder, a consistent approach from an experienced therapist may be of benefit.

As with younger patients with personality disorder, forming a therapeutic alliance can be difficult. Supportive, dynamic and cognitive approaches may 
be applicable, depending on the presenting complaint. It is important to have a consistent approach, with firm boundaries and good communication between the professionals involved. It is also important to involve the carers and to modify (if appropriate and possible) their reactions to untoward behaviour (Davison, 2002).

Research suggests that the current generation of older adults are positively inclined to believe that talking therapy can help most people with depression and that they prefer psychological therapies to medication (Rokke \& Scogin, 1995). So, although older people may be initially less inclined to discuss their psychological issues, they appear not to be resistant to the idea of psychological intervention.

Nevertheless, the application of the psychotherapies has been slow to develop for this population, mainly because of ageism, negative stereotypes about the treatability of older people and a perceived lack of psychotherapeutic theories for later life (Hepple, 2004). The predominance of organic or biological models of old age may have biased the field towards 'brain-based' rather than 'psychebased' explanations for illnesses in old age.

\section{Cognitive-behavioural therapy}

There is some evidence to suggest that adapted cognitive-behavioural therapy (CBT) is effective in addressing negative thoughts, identifying the dysfunctional cycles that can arise and intervening in unhelpful thinking patterns of older people (Thompson et al, 1987). In a recent article in this journal on the use of CBT with older people, Evans (2007) suggested how it might be modified to accommodate the degree of cognitive change and sensory and physical impairment encountered among such patients. Barrowclough et al (2001) demonstrated the effectiveness of CBT $v$. supportive counselling for anxiety symptoms.

In old age, people often face great challenges related to disability and loss - their social roles diminish and vanish, partners and friends die. These can precipitate lowered self-esteem and depression. Again, antecedent cluster $C$ personality traits might constitute predisposing factors.

\section{Cognitive analytic therapy}

Cognitive analytic therapy (CAT) may help patients to acknowledge some of these issues and work on them:

'Personality and relationships are not adequately described in terms of objects, conflicts or assumptions. They are sustained through an ongoing conversation within ourselves and with others - a conversation with roots in the past and pointing to the future. In their conversation with their patients, psychotherapists become important participants in this conversation and CAT, I believe, fosters the particular skills needed to find the words and other signs that patients need' (Ryle, 2000).

Cognitive analytic therapy has been applied to late-life problems of patients with narcissism, borderline personality traits and post-traumatic syndromes (Hepple \& Sutton, 2004).

\section{Psychodynamic therapy}

Psychodynamic therapy is at least as effective as CBT in dealing with depression in older people(Thompson et al, 1987) but the patient's age can affect the nature of the transference and countertransference. In most cases, one might anticipate that the patient will be older-perhaps by a great deal - than the therapist, and this may be worth considering at the outset, during patient allocation and supervision.

\section{Dialectical behavioural therapy}

Older people with personality disorder who become depressed have been shown to be less responsive to depression-specific therapies (Robins, 2003). In such cases, it appears that dialectical behavioural therapy may show promise (Lynch, 2000). An adaptation of behavioural therapy, dialectical behavioural therapy aims to promote change in emotional 'dysregulation' (Robins, 2003). Lynch found that it reduced interpersonal stress, hopelessness, avoidant, detached and emotional coping strategies, and also reduced dependency on, and desire to please, others.

\section{Supportive psychotherapy}

Supportive psychotherapy may be helpful for individuals with personality disorders who manifest low self-esteem and low self-confidence; it may also assist them in problem-solving and reducing the risk of future relapses or deterioration (Bloch, 1979). Psychodynamically oriented supportive therapy may help people to strengthen their 'ego function' and promote a better adaptation to reality (Rockland, 1989). Personality changes often occur in dementia, and supportive psychotherapy may help affected patients and also provide some support for their carers (Junaid \& Hegde, 2007).

\section{Family therapy}

Likewise, family therapy may assist the families of people with dementia accompanied by personality change; it may be especially useful when 
counselling relatives before the diagnosis is revealed (Qualls,2000). It can also inform awareness of family dynamics that are affecting the patient (Hepple, 2004).

\section{Nidotherapy}

Among younger people, there is growing evidence that nidotherapy may help to achieve a better fit, within the community, for people with personality disorders. It comprises a systematic adjustment of the environment to suit the needs of the individual (Tyrer \& Bajaj, 2005). The principles of nidotherapy might be applied to an older population to facilitate better coping skills and social functioning by manipulating their physical and social environment. The most obvious way of doing this is to offer patients access to residential care.

\section{Conclusions}

The literature concerning personality disorder among older people is currently quite sparse. This might be because personality disorders themselves have been rather contentious and, traditionally, old age psychiatry services have tended to focus on the management of dementia and the major Axis I disorders. However, it is likely that a greater number of patients with persistent Axis II disorders will survive into old age. Now would be a good time for psychiatric researchers to investigate the complex needs and issues associated with ageing among this group of people.

\section{Declaration of interest}

None.

\section{References}

Abrams, R. C. \& Horowitz, S. V. (1996) Personality disorders after age 50: a meta-analysis. Journal of Personality Disorder, 10, 271-281.

Barrowclough, C., King, P., Colville, J., et al (2001) A randomised trial of effectiveness of cognitive-behavioural therapy and supportive counselling for anxiety symptoms in older adults. Journal of Consulting and Clinical Psychology, 69, 756-762.

Bloch, S. (1979) Supportive psychotherapy. An Introduction to the Psychotherapies (ed. S. Bloch), pp. 294-319. Oxford University Press.

Bouman, W. P. \& Pinner, G. (2002) Use of atypical antipsychotic drugs in old age psychiatry. Advances in Psychiatric Treatment, 8, 49-58.

Camus, V., de Mendonca Lima, C. A., Gaillard, M., et al (1997) Are personality disorders more frequent in early onset geriatric depression? Journal of Affective Disorder, 46, 297-302.

Davison, S. E. (2002) Principles of managing patients with personality disorder. Advances in Psychiatric Treatment, 8, 1-9.

De Alarcon (1964) Hypochondriasis and depression in the aged. Gerontology Clinic (Basel), 55, 266-277.

Devanand, D. P. (2002) Comorbid psychiatric disorders in late life. Biological Psychiatry, 52, 236-242.
Devanand, D. P., Turret, N., Moody, B. J., et al (2000) Personality disorders in elderly patients with dysthymic disorder. American Journal of Geriatric Psychiatry, 8, 188-195.

Engels, G. I., Duijsens, I. J., Haringsma, R., et al (2003) Personality disorders in the elderly compared to four younger age groups: a cross-sectional study of community residents and mental health patients. Journal of Personality Disorder, 17, 447-459.

Evans, C. (2007) Cognitive behavioural therapy with older people. Advances in Psychiatric Treatment, 13, 111-118.

Fazel, S., Hope, T., O'Donnell, I., et al (2001) Hidden psychiatric morbidity in elderly prisoners. British Journal of Psychiatry, 179, 535-539.

Fuchs, T. (1999) Patterns of relation and premorbid personality in late paraphrenia and depression. Psychopathology, 32, 70-80.

Hansberry, M. R., Chen, E. \& Gorbien, M. J. (2005) Dementia and elder abuse. Clinics in Geriatric Medicine, 21, 315-332.

Hepple, J. (2004) Psychotherapies with older people: an overview. Advances in Psychiatric Treatment, 10, 371-377.

Hepple, J. \& Sutton, L. (eds) (2004) Cognitive Analytic Therapy in Later Life. A New Perspective on Old Age. Brunner-Routledge.

Herrmann, N. \& Lanctot, K. L. (2006) Atypical antipsychotics for neuropsychiatric symptoms of dementia: malignant or maligned? Drug Safety, 29, 833-843.

House of Commons Health Committee (2004) Elder Abuse: Second Report of Session 2003-04. Volume 1: Report, together with Formal Minutes. TSO (The Stationery Office). http:// www.publications.parliament.uk/pa/cm200304/cmselect/ cmhealth/111/11101.htm

Junaid,O.\&Hegde,S. (2007)Supportivepsychotherapyindementia. Advances in Psychiatric Treatment, 13, 17-23.

Kroessler, D. (1990) Personality disorder in the elderly. Hospital and Community Psychiatry, 41, 1325-1329.

Kunik, M. E.,Mulsant, B. H., Rifai, A. H., et al (1994) Diagnostic rate of comorbid personality disorder in elderly psychiatric inpatients. American Journal of Psychiatry, 151, 603-605.

Kurrle, S. E., Sadler, P. M. \& Cameron, I. D. (1991) Elder abuse: an Australian case series. Medical Journal of Australia, 155, 150-153.

Landes, A. M., Sperry, S. D. \& Strauss, M. E. (2005) Prevalence of apathy, dysphoria and depression in relation to dementia severity in Alzheimer's disease. Journal of Neuropsychiatry and Clinical Neurosciences, 17, 342-349.

Lynch, T. R. (2000) Treatment of elderly depression with personality disorder comorbidity using dialectical behaviour therapy. Cognitive and Behavioural Practice, 7, 468-477.

Petry, S., Cummins, J. L., Hill, M. A., et al (1989) Personality alterations in dementia of Alzheimers type: three year follow up study. Journal of Geriatric Psychiatry and Neurology, 2, 203-207.

Qualls, S. H. (2000) Therapy with ageing families: rationale, opportunities and challenges. Aging and Mental Health, 4, 191-199.

Robins, C. (2003) Dialectical behavior therapy for borderline personality disorder. Psychiatric Annals, 32, 608-616.

Rockland, L. H. (1989) Supportive Therapy: A Psychodynamic Approach. Basic Books.

Rokke, P. D. \& Scogin, F. (1995) Depression treatment preferences in younger and older adults. Journal of Clinical Geropsychology, 1, 243-257.

Rosenthal, M., Stelian, J., Wagner, J., et al (1999) Diogenes syndrome and hoarding in the elderly: case reports. Israel Journal of Psychiatry and Related Sciences, 36, 29-34.

Ryle, A. (2000) 'What Are The Origins of CAT?'. Association for Cognitive Analytic Therapy. http://www.acat.me.uk/ catorigins.php

Sanderson, W., Wetzler, S., Beck, A., et al (1994) Prevalence of personality disorders among patients with anxiety disorders. Psychiatry Research, 51, 167-174.

Speer, D. C. \& Bates, K. (1992) Comorbid mental and substance disorders among older psychiatric patients. Journal of the American Geriatric Society, 40, 886-890.

Stone, M. H. (1993) Long-term outcome in personality disorders. British Journal of Psychiatry, 162, 299-313

Stone, M. H., Hurt, S. W. \& Stone, D. K. (1987) The PI-500: Long term follow-up of borderline in-patients meeting DSM-III criteria. I: Global outcome. Journal of Personality Disorders, 1, 291-298. 
Stone, J., Townend, E., Kwan, J., et al (2004) Personality change after stroke: some preliminary observations. Journal of Neurology, Neurosurgery and Psychiatry, 75, 1708-1713.

Thompson, L., Gallagher, D. \& Breckenridge, J. S. (1987) Comparative effectiveness of psychotherapies for depressed elders. Journal of Consultant and Clinical Psychology, 55, 385-390

Tyrer, P. \& Bajaj, P. (2005) Nidotherapy: making the environment do the therapeutic work. Advances in Psychiatric Treatment, 11, 232-238.

Volkow, N. D., Gur, R. C., Wang, G., et al ( 1998) Association between decline in brain dopamine activity with age and cognitive and motor impairment in healthy individuals. American Journal of Psychiatry, 155, 344-349.

Wattis, J. (1998) Personality disorder and alcohol dependence. Seminars in Old Age Psychiatry (eds R. Butler \& B.Pitt), pp. 163-179. Gaskell.

World Health Organization (1992) The ICD-10 Classification of Mental and Behavioural Disorders: Clinical Descriptions and Diagnostic Guidelines. WHO.

Zanarini, M. C., Frankenburg, F. R., Hennen, J., et al (2003) The longitudinal course of borderline psychopathology: 6-year prospective follow-up of the phenomenology of borderline personality disorder. American Journal of Psychiatry, 160, 274-283.

\section{MCQs}

1 The following statements are correct:

a as age advances, impulsivity, aggression and promiscuity decrease

b among older people, antisocial and borderline personality traits become more common

c cluster A personality disorders are most prevalent among older people

d dementing illnesses always precipitate changes in personality

e among older people, trial of medication is always of help for personality disorder.

2 The following are very commonly associated with personality disorders in older people:

a depression

b metachromatic leukodystrophy

c anorexia nervosa

d schizophrenia

e autism.
3 When managing personality disorders in older adults:

a medications may not be useful in treating comorbid functional illnesses

b low-dose antipsychotics may help control disturbed behaviour

c older people believe that psychotherapy will not be useful for them

d psychotherapies have not been very useful

e ECT is a first-line treatment.

4 The following therapies have shown benefits in the treatment of personality disorder in later life:

a parenting therapy

b cognitive analytic therapy

c counselling

d homoeopathy

e aromatherapy.

5 The following 'rules of thumb' can be helpful in treating personality disorder:

a treat associated Axis I disorders

b support the patient only - exclude the carer(s)

c always try medication

d never use a psychotherapy

e never investigate underlying physical illnesses.

\begin{tabular}{|llllll|}
\hline MCQ answers & & & & \\
1 & & & & & \\
a T & a T & a F & a F & a T \\
b F & b F & b T & b T & b F \\
c F & c F & c F & c F & c F \\
d F & d F & d F & d F & d F \\
e F & e F & e F & e F & e F \\
\hline
\end{tabular}

